\title{
Impact of Dual co-teaching on the Understanding of Genetics by Grade 12 Pupils at Chambishi Secondary School in Kalulushi District of Zambia
}

\author{
Alex Mumba ${ }^{1 *}$, Alfred M. Sichilima ${ }^{2}$ \\ ${ }^{1}$ Department of Natural Sciences, Chambishi Secondary School, Kalulushi District, Copperbelt Province, Zambia \\ ${ }^{2}$ Department of Mathematics and Natural Sciences, Copperbelt University, Zambia
}

\begin{abstract}
The study investigated the impact of dual co-teaching on the understanding of genetics at Chambishi Secondary School in Kalulushi District of Zambia. A two-group pretest-posttest true experimental research design was used in which quantitative data were collected using a genetics achievement test and a Likert type questionnaire. The study sample consisted of 120 respondents who were drawn from all the six grade 12 classes and 1 biology teacher who worked as a co-teacher. Descriptive statistics such as means, standard deviations and median were used to summarize the data while the hypotheses were tested at 0.05 alpha level using Mann Whitney $U$ test and independent t-test using SPSS version 20. The major findings of the study were that the experimental group which was exposed to dual co-teaching posted a higher achievement rate in genetics assessments and improved attitude compared to the control group. The results also showed that there no statistically significant difference in the performance of males and females in genetics. The improved performance was due to the fact that dual co-teaching creates stronger and more creative lessons through improved student-teacher relationships, additional supports and diversity in the classroom. The study recommended that dual co-teaching should be institutionalized and explored in other subjects.
\end{abstract}

Key words: Achievement, Attitude, Dual co-teaching, Gender, understanding, Lecture method.

\subsection{INTRODUCTION}

Biology is one of the major subject taught at secondary school level in Zambia. Quite literally, biology means the study of life. Biology is also defined as a science that seeks to understand, explain, and even control the living world [1]. Biology is a broad field which consist of many branches. These include zoology which is the study of animals, botany which is the study of plants while microbiology deals with the study of microscopic Organisms. Others branches include ecology which involves the study of interactions between biotic and abiotic factors while the other one is genetics which is concerned with heredity and variations [2].

Genetics is a biological discipline which involves the study of cells, individuals, their offspring, and the population within which the organism lives. Genetics is one of the main topics taught at senior secondary school level particularly at grade 12 level. This discipline has been part of the Zambian biology syllabus since 1973 [3].The sub-topics covered under genetics include; mitosis and meiosis, variations, monohybrid crosses, sex determination, sex linked diseases, co-dominance and mutation [4]. Genetics in general is considered to be one of the most difficult topics in biology by many secondary school pupils at least through the experience of the researcher who happens to be a teacher of biology and through many other studies done by other researchers.

There are many studies done to determine the most difficult topics in biology. The results of one study which sampled a number of pupils showed that five of the six topics which were recorded as difficult were from the field of genetics. These are mitosis and meiosis, alleles and genes, genetic engineering, monohybrid and dihybrid crosses and linkages [5]. This shows that the general field of genetics is still a problem to many learners. This perception is also shared by a number of experienced teachers and the national examination bodies of some countries [5]. For instance, the chief examiners report for biology paper two in the Zambian school certificate examinations showed that the national average pass rate was as low as $21.29 \%$ in 2015 [6] and $24.14 \%$ in 2016 [7]. The report further states that the question on genetics was poorly answered and in most cases just left blank. This greatly contributed to the overall poor results in this paper [6]. Another study done to assess the nature and causes of poor performance in biology at grade 12 identified genetics as one of the topics contributing to poor performance in biology national examinations [8]. 
The fact that pupils have continued performing poorly in genetics is evidence enough that previous studies done did not yield the desired results. The researcher therefore, propose to use dual co-teaching technique as an additional method or strategy for effective teaching of genetics. Dual co-teaching is the practice of having two teachers together in a classroom to share responsibilities of planning, instructing, and assessing students [9]. It is a basis for educators to share ideas, teach one another, conduct classroom investigation, reflect on current practices, build new skills and solve problems in the work place. Co-teaching is a concept under meaningful learning and mostly used to enhance teaching skills among teachers.

\subsection{Problem Statement}

The problem of poor performance in biology country wide and Chambishi secondary school in particular has persisted over a number of years. For instance, results analysis for Chambishi Secondary School shows that the average pass percentage in biology school certificate examinations was $50.2 \%$ and $52.1 \%$ in 2016 and 2017 respectively. This performance is definitely not impressive. Genetics has been cited as one of the topics which contributes significantly to this poor performance. Many stakeholders such as the examination council of Zambia, scholars, teachers and pupils have all agreed that genetics particularly inheritance, has been a challenging topic over years hence contributing greatly to the poor performance in School certificate examinations [3]. Some efforts have been tried such as conducting continuous development programs (CPD) and holding of workshops to help address this problem but the efforts have not had much impact. The current scenario is that genetics has remained a challenging topic for both teachers and learners. Therefore, there is need for more studies in this field to help make the topic less challenging. To my knowledge, no one has ever used dual co-teaching to study genetics in Kalulushi district in general and Chambishi secondary school in particular.

\subsection{Objectives of the study}

The objectives of the study were;

1. To determine the impact of dual co-teaching on students' achievement in genetics.

2. To establish if performance of girls and boys differ when both are exposed to dual co-teaching strategy.

3. To determine pupils' attitude towards genetics when taught using dual co-teaching method and lecture method.

\subsection{LITERATURE REVIEW}

\subsection{How genetics is mostly taught}

Effective learning to a large extent depends on the choice of method/s used. The nature of biology requires those methods which put learners at the centre of learning while the teacher plays the role of facilitator. These methods are the most recommended in the teaching of genetics because they involve both hands on and minds on activities. These methods stress learning by doing and active involvement in experiencing, formulating ideas and problem solving, hence learners becomes critical thinkers and problem solvers [10]. This is in line with the theory of constructivism which stipulates that the learners must be allowed to construct knowledge on their own for meaningful learning to occur. Unfortunately, studies done shows that most teachers usually use traditional methods of teaching such as lecture which do not encourage meaningful learning hence contributing to poor performance in this field [11]. This is because such learners cannot construct new knowledge because they remain passive most part of the lesson.

Lecture method is defined as a teaching method used for passive assimilation by students [10]. This method creates very little room of asking questions by the learners. The teacher also cannot be sure how much the students have grasped and also the teacher faces challenges in identifying the needs of individual pupils, and evaluation of methodology. This is definitely not a good method of teaching genetics because students' involvement is very minimal and also minimizes feedback from the learners.

\subsection{Studies done on dual co-teaching teaching technique}

Co-teaching is the practice of having two or more teachers together in a classroom to share responsibilities of planning, instructing, and assessing students [9]. However, in dual co-teaching, only two teachers are involved. Another way of saying this is that dual co-teaching is a fun way for students to learn from two educators who may have different ways of thinking or teaching. Co-teaching can be likened to a marriage. Partners must establish trust, develop and work on communication, share the chores, celebrate and work together creatively to overcome the inevitable challenges and problems and anticipate conflict and handle it in a constructive way [12]. The twenty first century notion of co-teaching places it within the context of some of the most innovative practices in education. The reassignment of existing personnel to co-teaching teams results in a knowledge and skill exchange among team members and higher teacher to student ratios, outcomes that benefit more students than the individual 
student in need of instructional support. This is considered to be a dynamic structure in which complex work is more likely to be accomplished and novel instruction is more likely to be crafted to meet individual student needs [13].

It has been observed that having two teachers leading a classroom opens up many opportunities for students [14]. One benefit of co-teaching is that it has increased opportunities to develop student-teacher relationships because this education model facilitates teaching practices such as individual student-teacher conferences, teacher led small group activities and remediation sessions based on student need. The teaching model also provide opportunities for specialised instruction when needed and also the students are able to benefit from the additional supports, resources, and diversity in the classroom. Co-teaching also creates stronger and more creative lessons due to teachers sharing the planning process with each other. Furthermore, teachers are able to support one another by complimenting each other's weaknesses, building camaraderie and dividing the work load in the classroom. For proper implementation of co-teaching, there must be mutual respect in a co-teaching relationship. Ideas must be shared openly and respecting each other's opinion [15]. Clarifying the role of each teacher during the lesson is also vital [16]. Coteaching works better when the partners agree on who does what and when.

Co-planning is other factor which enhances co-teaching. Co-planning time is a key factor in making a co-taught classroom thrive. This is an opportunity for both teachers to plan their lessons together and get a better understanding of the content and the students. Communication is yet another important factor in co-teaching. Planning is one thing; constant communication is another. Not only should co-teachers frequently plan for what content will be covered, how material will be taught, and how students will be assessed, they should also regularly communicate in less formal ways. For instance, co-teachers may talk about assessments to see which areas are lacking and what measures can be put in place. They may also talk about the challenges and progress which specific students are making [17].

There are six methods or models that are used in implementing co-teaching [18]. The first model involves one teaching and the other one observing (one teach, one observe). In this model, one teacher instructs while the other observes students to identify issues and assess their performance. This method allows the observing teacher to provide feedback on which content and activities are most effective for students, allowing the co-teaching pair to continually improve their practice and best meet the needs of all students in their classroom. The second model involves one teacher teaching while the other one is drifting (one teach, one drift). In this model, one teacher instructs while the second teacher provides additional assistance and support to students as needed.

The third model is called station teaching. With station teaching, the lesson is divided into segments as the teachers each instruct part of the lesson at independent stations or rotate between groups of students. This allows teachers to provide specialised support when delivering content in areas they may have more expertise in, or if their style better fits a certain part of a lesson. Parallel teaching is a model in which the teachers plan jointly and later divides the class into two groups and they instruct each group with the same content simultaneously. In this arrangement, the smaller groups allow closer supervision and more opportunities for interaction between the students and teacher.

The fifth model is called alternate teaching. In this model, one teacher handles a larger group, while the other one teaches a small group who need specialised attention and additional support. The sixth and last model is called team teaching. Team teaching requires the strongest partnerships, but can be one of the most fulfilling methods of co-teaching. With team teaching, the coteachers share responsibility and deliver instruction at the same time as a "tag team". In implementing co-teaching models, a coteaching pair doesn't necessarily use the same teaching model everyday. The method chosen by the teachers is determined by their individual teaching styles, the unique needs of the classroom, and the lesson being taught. Co-planning time give both teachers opportunity to identify what model should be used during the lessons. When the co-teachers are prepared to use various models and are comfortable sharing their classroom as equals, the experience for students can be seamless and effective [19].

This is consistent with the theory of social constructivism which makes the assertion that, "all higher functions originate as actual relationship between individuals" [20]. It suggests that as humans participate in common, collaborative activities, they learn and internalize new strategies and knowledge as a new result of collective thinking with other humans. Teachers, regardless of their level of experience, can engage in ways that allow them to individually transform and internalize the concepts needed to improve their practice. Studies have shown that skill development alone is not enough to improve educator's teaching repertoire. However, educator's teaching prowess can be improved through the use of innovative learning strategies such as co-teaching to supplement traditional teaching practices such as lecture method.

As observed in the literature above, dual co-teaching assists teachers on their needs so they can become better teachers. It also helps them to reflect and get feedback on what they are doing in class. Collaborative-planning with peers enriches teachers with variety methodologies, questioning techniques as well as class management resulting in a conducive environment where social interaction among learners is encouraged. The theory of social constructivism advocates for enhanced social interaction in learning as a vital component among learning individuals. It further emphasizes that learning takes place through interaction with other students, teachers and the world at large. The researcher used dual co-teaching as an approach to the teaching of genetics with the main objective of trying to find out if dual co-teaching can help to enhance pupils' achievement in genetics. 


\subsection{Studies done on gender in science.}

Gender is used to describe those characteristics of women and men, which are socially constructed. It refers to socially constructed roles, behaviours and activities that a given society considers appropriate for men and women [21]. In Zambia though progress has been made in enhancing the socio economic status of women, they still remain among the disadvantaged and marginalized. This is particularly evident in the feminisation of poverty as reflected in the limited access to employment, educational services and managerial decision making process. The disadvantaged status of women and girls is also strongly marked in the education sector particularly in STEM (Science, technology, engineering and mathematics) subjects [22]. In general, there is one female student to every four males, meaning that female students account for only $20 \%$ of total university enrolments. The majority of these are in arts and humanities areas with females who take some form of science programme accounting for only $5 \%$ of total university enrolments [22].

The low enrolment in science related subjects biology inclusive is a strong indication that females regard science subjects to be more challenging than their male counterparts. The science is narrowed to biology and the branch of genetics in particular. The ministry of education in its national educational policy document called, "Educating our future", indicates that institutional, social-cultural and personal factors combine to impede girls in realizing their potential through education. Personal factors include a negative image which the school frequently reinforces and radical socialization to be passive and submissive. The belief that boys perform better than girls in science which is perpetuated by both teachers and members of the public has resulted in selffullfilling prophecies in girls. In this vein, the ministry of education in Zambia seeks to reverse this by establishing a special bursary scheme for girls and will provide scholarships for girls who excel in mathematics, science and technology plus providing an equal number of school places for girls and boys at all school levels.

Gender differences may perhaps influence student's perception on, and achievement in biology difficult topics such as genetics. According to the European Union, gender differences in science achievement are the smallest [23]. It was further stressed that despite performing equally well as boys in most countries, girls tend to have a weaker self-concept in science, biology inclusive than males i.e. on average, girls had lower levels of belief in their science abilities than boys. The reason why boys perceive genetics easier than girls could be attributed to socialization factors and classroom experiences leading to low self-esteem and passive dependent behaviour among girls. This is in agreement with a study done in order to find answers as to whether there is any difference in the perception of male and female students of difficult biology topics, it was revealed that gender has no significant difference on student's perception of difficult biology topics [24].

Another study suggested that gender does not seem to affect pupils' overall views about difficult topics in biology [25]. This result could be an indication that biology in general and genetics in particular pose same level of difficulty to both male and female students. This shows that the student's perception of difficult topics in biology is not a function of gender. These findings are supported by another study which discovered that the effect of sex in performance in biology between male and female is not statistically significantly [26]. However, the results of this study contrasted with another study whose results revealed that there exist gender differences in biology achievement in the schools [27]. These findings were consistent with another study which discovered that there were more girls than boys who perceive more biological concepts as difficult to learn [28]. This controversy justifies why further research must be done to find the real situation regarding the effect of gender on the understanding of biology in general and genetics in particular.

\subsection{METHODOLOGY}

The study employed the experimental research design specifically the two group pretest-posttest experimental research design to collect quantitative data. The sample population comprised of 120 grade 12 pupils and one teacher giving a total of 121 respondents. The pupil population was picked using simple random sampling with replacement while the only teacher in the sample was selected purposively. Furthermore, the selected pupils were randomly assigned to the control and experimental groups each having 60 participants only. A genetics achievement test was used to collect quantitative data on pupils' understanding of genetics while a Likert attitude questionnaire was used to collect quantitative data on the attitude of pupils towards genetics before and after the administration of the treatment.

The study was analyzed using descriptive statistics due to the quantitative nature of the data collected. Data which was normally distributed was analysed using independent samples t-tests. On the other hand, data which was not normally distributed was analysed using Mann-Whitney U tests.

\subsection{FINDINGS AND DISCUSSION}




\subsection{What is the impact of dual co-teaching on students' achievement in genetics?}

The process of assessing this objective started with running a normality test on all the numerical variables used for making comparisons and below are the results in table 1 .

Table 1: Test for normality for all the numerical variables

\begin{tabular}{|c|c|c|c|c|c|c|}
\hline & \multicolumn{2}{|c|}{ Kolmogorov-Smirnov $^{\mathrm{a}}$} & \multicolumn{2}{|c|}{ Shapiro-Wilk } & \multirow[b]{2}{*}{ df } & \multirow[b]{2}{*}{ Sig. } \\
\hline & Statistic & df & Sig. & Statistic & & \\
\hline PRE-TEST (BOTH GROUPS) & 0.086 & 120 & 0.028 & 0.970 & 120 & 0.009 \\
\hline POSTTEST (BOTH GROUPS) & 0.092 & 120 & 0.015 & 0.974 & 120 & 0.020 \\
\hline EXPERIMENTAL GROUP PRE-TEST & 0.091 & 60 & 0.200 & 0.962 & 60 & 0.058 \\
\hline EXPERIMENTAL GROUP POST-TEST & 0.081 & 60 & 0.200 & 0.977 & 60 & 0.316 \\
\hline
\end{tabular}

a. Lilliefors Significance Correction

From Table 1 above, the p-values for the pre-test and the post-test were less than the set alpha value of 0.05 . This means that performance scores for the pre-test and post-test scores is not normally distributed hence a non-parametric test (Mann-Whitney $U$ test) was used to compare mean scores of the experimental and control group. Table 1 also shows that the p-values of experimental group pre-test and the experimental group post-test were greater that the set alpha of 0.05 . This means that the performance scores for the experimental group pre-test and the experimental group post-test were normally distributed. Therefore a t-test was used to compare the performance of male and female learners in the experimental group. Table 2 below shows the descriptive statistics of the pre-test performance of the experimental and the control group. In this case the measure of central tendency used was the mean rank from a Mann-Whitney $\mathrm{U}$ test.

Table 2: Descriptive statistics for the pre-test performance of the experimental and control group

\begin{tabular}{lllll}
\hline & GROUP & $\mathrm{N}$ & Mean Rank & Sum of Ranks \\
\hline \multirow{3}{*}{ PRE-TEST } & EXPERIMENTAL GROUP & 60 & 60.73 & 3643.50 \\
& CONTROL GROUP & 60 & 60.28 & 3616.50 \\
\cline { 2 - 5 } & Total & 120 & & \\
\hline
\end{tabular}

From Table 2 above, the mean ranks of the experimental group and the control group are 60.73 and 60.23 respectively. Table 3 below goes further to test if there was a significant difference between the mean ranks of the two groups.

Table 3: Mann-Whitney $U$ test for the pre-test performance of the experimental and the control group

\begin{tabular}{ll}
\hline & PRETEST \\
\hline Mann-Whitney U & 1786.500 \\
Wilcoxon W & 3616.500 \\
$\mathrm{Z}$ & -0.071 \\
Asymp. Sig. (2-tailed) & 0.943 \\
\hline a. Grouping Variable: GROUP &
\end{tabular}

Table 3 above shows that the p-value of the pre-test performance is 0.943 which was greater than the set alpha value of 0.05 . Therefore the null hypothesis was retained. This meant that there was no statistically significant difference between the performance of the experimental group and the control group. Consequently, it meant that the experimental group and the control group had the same knowledge level in Genetics before they were taught using dual co-teaching and lecture method respectively. 
Table 4 below shows the descriptive statistics of the post-test performance of the experimental group and the control group. The experimental group and the control group had mean ranks of 82.74 and 38.26 respectively.

Table 4: Descriptive statistics for the post-test performance of the experimental and control group

\begin{tabular}{lllll}
\hline & GROUP & N & Mean Rank & Sum of Ranks \\
\hline \multirow{3}{*}{ POST-TEST } & EXPERIMENTAL GROUP & 60 & 82.74 & 4964.50 \\
& CONTROL GROUP & 60 & 38.26 & 2295.50 \\
& Total & 120 & & \\
\hline
\end{tabular}

Table 5 below show the results of a Mann-Whitney U test that compares the mean ranks of the experimental group and the control group for statistical difference.

Table 5: Mann-Whitney $U$ test for the post-test performance of the experimental and the control group

\begin{tabular}{ll}
\hline & POSTTEST \\
\hline Mann-Whitney U & 465.500 \\
Wilcoxon W & 2295.500 \\
Z & -7.010 \\
Asymp. Sig (2-tailed) & 0.000 \\
\hline a. Grouping Variable: GROUP &
\end{tabular}

Table 5 shows that the p-value was 0.000 , which was less than the set alpha value of 0.05 . Therefore the null hypothesis was rejected in favour of the alternative hypothesis. This meant that there was a significant difference between the mean rank of the experimental group and the control group. Since the experimental group outperformed the control group. It can be concluded that dual co-teaching had a positive impact on the performance of learners in genetics. This is because co-teaching creates more opportunities for one on one interaction between students and teachers, leading to stronger relationships. All students tend to benefit from the additional supports, resources, and diversity in the classroom [14]. This is also due to the fact that co-teaching promotes professional development among teachers which also makes them improve their teaching skills hence benefitting the learners even more. Also the learners tend to benefit more from the input of two teachers at the same time. They tend to be more attentive as teachers keep on complimenting one another during the lessons unlike in the class taught in a traditional way.

The improvement in performance in the experimental group was also due to the fact that dual co-teaching promotes meaningful learning where pupils are able to construct their own knowledge through interactions with their peers [20]. Despite the findings of this study conforming to a number of studies on the effectiveness of co-teaching, some scholars have expressed misgivings regarding the use of co-teaching. However, the implementation of co-teaching comes with challenges such as requiring a lot more planning and preparation [29].

\subsection{Does the performance of girls and boys differ when both are exposed to dual co-teaching strategy?}

Table 6 below shows the descriptive statistics of the pre-test performance of the male and female learners on the experimental group. The table shows that the mean performance of the experimental group and the control group is $36.54 \%$ and $35.53 \%$ respectively.

Table 6: Descriptive statistics for the pre-test performance of the male and female learners in the experimental group 
International Journal of Advances in Scientific Research and Engineering (ijasre), Vol 5 (12), December-2019

\begin{tabular}{llllll}
\hline & GENDER & $\mathrm{N}$ & Mean & Std. Deviation & $\begin{array}{l}\text { Std. } \\
\text { Error Mean }\end{array}$ \\
\hline \multirow{2}{*}{ PRE-TEST } & MALE & & & & 2.001 \\
& FEMALE & 24 & 36.54 & 9.802 & 1.623 \\
\hline
\end{tabular}

Table 7 below goes on to present the results of an independent samples t-test on the pre-test performance of the male and female learners.

Table 7: Independent samples t-test for the pre-test performance of the males and females in the experimental group

\begin{tabular}{|c|c|c|c|c|c|c|c|}
\hline & & \multirow{2}{*}{\multicolumn{2}{|c|}{$\begin{array}{l}\text { Levene's Test for } \\
\text { Equality of Variances }\end{array}$}} & \multicolumn{3}{|c|}{ t-test for Equality of Means } & \multirow[b]{3}{*}{ Mean Difference } \\
\hline & & & & & & & \\
\hline & & $\mathrm{F}$ & Sig. & $\mathrm{t}$ & df & $\begin{array}{l}\text { Sig. }(2- \\
\text { tailed) }\end{array}$ & \\
\hline EXPERIMENTAL & Equal variances assumed & 0.712 & 0.402 & 0.394 & 58 & 0.695 & 1.014 \\
\hline GROUP PRETEST & Equal variances not assumed & & & 0.394 & 49.220 & 0.696 & 1.014 \\
\hline
\end{tabular}

The table shows that the p-value is 0.695 , which is greater than the set alpha value of 0.05 . Therefore the null hypothesis was retained. This meant that there was no significant difference Therefore, both the male and female learners started off at the same level before they were taught genetics using dual co-teaching.

The post-test performance of the male and female learners in the experimental group were then compared and table 8 presents the results of the descriptive statistics.

Table 8: Descriptive statistics for the post-test performance of the male and female learners in the experimental group.

\begin{tabular}{lllccc}
\hline & GENDER & $\mathrm{N}$ & Mean & Std. Deviation & $\begin{array}{l}\text { Standard } \\
\text { Error Mean }\end{array}$ \\
\hline EXPERIMENTAL & MALE & 24 & 55.42 & 9.399 & 1.919 \\
GROUP POST-TEST & FEMALE & 36 & 51.11 & 8.021 & 1.337 \\
\hline
\end{tabular}

The table shows that the mean performance of the male and female learners in the experimental group was $55.42 \%$ and $51.11 \%$ respectively. Table 9 below further tests these mean performances for significant differences using an independent samples ttest.

Table 9: Independent samples t-test for the post-test performance of the males and females in the experimental group

Levene's Test for t-test for Equality of Means
Equality
Variances

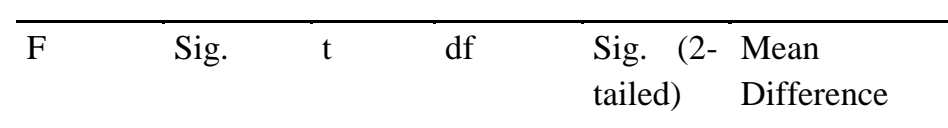

\begin{tabular}{llllllll}
\hline & $\begin{array}{l}\text { Equal variances } \\
\text { assumed }\end{array}$ & 1.594 & 0.212 & 1.901 & 58 & 0.062 & 4.306 \\
ERPERIMENTAL & & & & & & \\
& $\begin{array}{l}\text { Equal variances not } \\
\text { assumed }\end{array}$ & & 1.841 & 43.946 & 0.072 & 4.306
\end{tabular}

Table 9 shows that the p-value of the independent samples t-test is 0.062 , which is greater than the set alpha value of 0.05 . Therefore the null hypothesis was retained. This means that there was no statistically significant difference between the mean 
performances of the male and female learners after they had been taught using dual co-teaching strategy. In this regard, it can be concluded that both male and female learners respond well to dual co-teaching strategy. Independent t-test was used to answer this research question because the pretest and posttest scores of pupils in the experimental group were found to be normally distributed according to table 1 . These results are in agreement with other findings which showed that, there is no significant difference in the average achievement of girls and boys in genetics [30]. The result could be an indication that genetics pose the same level of difficult to both girls and boys.

Studies done by another researcher discovered that girls perform nearly the same as boys in biology and genetics in particular because girls show high positive attitude in biology than they do in the other sciences (physics \& chemistry) [31]. He further discovered that boys demonstrate positive attitude in physics compared to biology. This has helped to narrow the performance gap in biology between girls and boys. However, these results contrasted with other studies which revealed that there exist gender differences in biology achievement in the schools with boys performing better than girls in biology in general and genetics in particular [32].

4.3 What is the impact of dual co-teaching on students' attitude towards genetics?

Table 10 presents the descriptive statistics of the attitude of the experimental and the control group for the pre-test.

Table 10: Descriptive statistics for the pre-test attitude of the experimental and control group.

\begin{tabular}{l|llcl}
\hline & GROUP & $\mathrm{N}$ & Mean Rank & Sum of Ranks \\
\hline \multirow{4}{*}{ ATTITUDE } & EXPERIMENTAL GROUP & 13 & 13.19 & 171.50 \\
& CONTROL GROUP & 13 & 13.81 & 179.50 \\
& Total & 26 & & \\
& & & & \\
\end{tabular}

The mean ranks of the experimental group and the control group are 13.19 and 13.81 respectively. Table 11 below presents a Mann-Whitney $U$ test used to compare these mean ranks for any significant differences.

Table 11: Mann-Whitney $U$ test for the pre-test attitude of the experimental and the control group

\begin{tabular}{ll}
\hline & ATTITUDE \\
\hline Mann-Whitney U & 80.500 \\
Wilcoxon W & 171.500 \\
Z & -0.247 \\
Asymp. Sig. (2-tailed) & 0.805 \\
Exact Sig. [2*(1-tailed Sig.)] & $0.840^{\mathrm{b}}$ \\
\hline
\end{tabular}

a. Grouping Variable: GROUP

b. Not corrected for ties. 
Table 11 above shows that the p-value of the pre-test attitude is 0.840 which is greater than the set alpha value of 0.05 . This meant that there was no statistically significant difference between the attitude of the experimental group and the control group after pretested. Therefore, it meant that the experimental group and the control group had the same attitude towards Genetics before they were taught using dual co-teaching and lecture method respectively. Table 12 below shows the descriptive statistics of the posttest attitude of the experimental and the control group. The mean ranks of the experimental group and the control group are 16.88 and 10.12 respectively.

Table 12. Descriptive statistics for the post-test attitude of the experimental and control group

\begin{tabular}{lllll}
\hline & GROUP & N & Mean Rank & Sum of Ranks \\
\hline & EXPERIMENTAL GROUP & 13 & 16.88 & 219.50 \\
ATTITUDE POST_TEST & CONTROL_GROUP & 13 & 10.12 & 131.50 \\
& Total & 26 & & \\
\hline
\end{tabular}

Table 13 below further shows results of a Mann-Whitney U test used to test the mean ranks of the experimental and the control group for significant difference.

Table 13: Mann-Whitney $U$ test for the post-test attitude of the experimental and the control group

\begin{tabular}{ll}
\hline & ATTITUDE \\
\hline Mann-Whitney U & 40.500 \\
Wilcoxon W & 131.500 \\
$\mathrm{Z}$ & -2.350 \\
Asymp. Sig. (2-tailed) & 0.019 \\
Exact Sig. [2*(1-tailed Sig.)] & $0.022^{\mathrm{b}}$ \\
\hline
\end{tabular}

a. Grouping Variable: GROUP

b. Not corrected for ties.

Table 13 above shows that the p-value of the post-test attitude is 0.022 which is less than the set alpha value of 0.05 . Therefore, there was statistically significant difference between the attitude of the experimental group and the control group after being posttested. This implies that dual co-teaching improves the learners' attitude toward genetics. This is so because dual co-teaching increases more interactions between learners and teachers and among learners themselves. The students also get exposed to a variety of teaching styles and enhanced communication skills in form of small group activities. It also results in difficult concepts to be clearly explained since the teachers are complementing one another. These and many other attributes of dual co-teaching went a long way in improving learners' attitude.

The overall effect of these factors were seen in pupils slowly changing their attitude for the better. On the contrary, some students have been found to develop negative attitude after being exposed to co-teaching. Some studies have observed that students are likely to feel uncomfortable with co-teaching because some instructors appear disorganised or difficult to follow [33]. Furthermore, some students found co-teaching to be foreign and confusing at times especially when one has to follow both teachers instead of one and also the fact that each instructor has his/her own style of teaching. However, this study shows that the benefits of co-teaching outweighs the troubles it comes with. 


\subsection{CONCLUSION AND RECOMMENDATION}

The results showed that dual co-teaching improves the general performance and attitude of pupils in genetics. This is because coteaching creates more opportunities for one on one interaction between students and teachers, leading to stronger relationships. All students tend to benefit from the additional supports, resources, and diversity in the classroom as well as the input of two teachers at the same time. This is also due to the fact that co-teaching promotes professional development among teachers which also makes them improve their teaching skills hence benefitting the learners even more. The learners tend to be more attentive as teachers keep on complimenting one another during the lessons unlike in the class taught in a traditional way. Also the results showed that there was no statistically significant difference between the mean performances of the male and female learners after they had been taught using dual co-teaching strategy. This is because girls shows high positive attitude in biology than they do in the other sciences (physics \& chemistry).

Based on these findings, the following recommendations were suggested to the ministry of general education in Zambia. The ministry should consider improving, increasing and institutionalizing co-teaching practices in all schools in Zambia. The Zambia association for science education (ZASE) must consider developing a manual on the execution of dual co-teaching as well as providing professional development on collaboration and co-teaching.

\section{REFERENCES}

1. Verma, P.S \& Aggarwal, V.K (2005) Cell Biology, Genetics, Molecular Biology, Evolution \& Ecology.

S. Chand \& Company Limited: New Delhi, India.

2. Kent, M., (2000) Advanced Biology, Oxford University Press: Oxford, U.K, 1-2.

3. Haambokoma, C. (2007) "Nature and causes of Learning difficulties in Genetics at High School Level In Zambia" Journal of international Development \& Cooperation 13 (1), 1-9.

4. Curriculum Development Centre, CDC, (2013) High school biology syllabus. Lusaka; Ministry

5. Bahar, M., et al (1999). Revisiting Learning Difficulties in Biology: Journal of Biology Education, 33(2), 84-86.

6. Examination Council of Zambia, ECZ (2015) School Certificate \& General Certificate of Education Chief Examiners Report. ECZ; Lusaka, 83-85

7. Examination Council of Zambia, ECZ (2016) School Certificate \& General Certificate of Education Chief Examiners Report. ECZ; Lusaka, 80-83

8. Manda, K., (2012) Learning Difficulties Grade Twelve Pupils Experience in Biology. The case of Selected High Schools in Samfya District.

9. Stein, E. (2016). Elevating co-teaching through UDL. Wakefield, MA: CAST, Professional Publishing.

10. Petty, G., (2009). Teaching Today: A practical Guide $\left(4^{\text {th }}\right.$ Ed) Cheltenham, Nelson Thormes.

11. Ownu, G \& Haambokoma, C. (2012). "Towards a Culturally Relevant \& Socially Responsive Science Education”. University of Pretoria: Pretoria.

12. Villa, A \& Thousand, T. (2005) Creating and sustaining inclusive school. California state university, San Marcos.

13. Skrtic, T. (1991). The special education paradox. Equity as a way to excellence. Harvard Educational Review.

14. Ferguson, D., et al. (2000) Improving education. The promise of inclusive schooling [Brochure]. Newton, MA: National institute for urban school improvement.

15. Sacks, A. (2014). Blog post. Eight tips for making the most of co-teaching. Retrieved January 26, 2017, From http:// www.edweek.org/tm/articles/2014/10/15/ctqsackscoteaching.html

16. Dettmer, P., et al. (2009). Collaboration, consultation, and teamwork $\left(6^{\text {th }}\right.$ Ed.). Columbus, OH: Pearson.

17. Conderman, G., et al. (2009). Communicating and collaborating in co-taught classrooms. Teaching Exceptional Children Plus, 5(5). Retrieved January 26, 2017, from

http://files.eric.ed.gov/fulltext/EJ967751.pdf 
18. Cock, L \& Friend, M. (2004). Co-teaching: Principles, practices and pragmatics. Participants guide. Paper presented at New Mexico public education department, quarterly special educational meeting, Albuquerque. Santa Fe, NM: New Mexico public education department.

19. Nancy, L., et al (2008). "What makes Co-Teaching Work? Identifying the Essential Elements". Colleges teaching Methods \& Styles journal. 4(3) 43-48.

20. Vygotsky, L.S (1978), Mind in Society. Cambridge, M.A: Harvard University Press.

21. Kelly, M.J. (1996). The Origins and Development of Education in Zambia from Pre-colonial Times to 1996. Image Publishers Limited. Lusaka.

22. Ministry Of Education (MOE). (1996). Educating our future. Lusaka: Zambia Publishing House.

23. European Union EU, (2010). Gender Differences in Educational Outcomes: Study on the Measures Token and the current Situation in Europe. Education, Audiovisual and Cultural Executive Agency (EACEAP9 Eurydice) (http://www.eurydice.org).

24. Benjamin A.E \& Emmanuel O.F, (2017). Students' perceptions of difficult concepts in biology in Senior secondary schools in Lagos state. Lagos state University.

25. Mavrikaki, E., et al. (2012). Greek secondary school students' views about biology. International Journal of environmental and science education. 7(2): 217-232. Retrieved November 5, 2015, from http://www.ijese.com/IJESE-v7n2-Mavrikaki-et al. pdf.

26. Areola, E.O., (1995). An evaluation of the Nigerian integrated science programme. In UNESCO, Integrated science teaching in biology classrooms and their attitudes towards biology. Paper presented At the Annual meeting of the American Association Research, Chicago.

27. Nworgu, L.N., (2005). Effects of gender sensitization package (GSP) on student's achievement in Integrated science. Journal of STAN, 40(1\&2), 74.

28. Tekkaya, C., et al (2001) "Biology Concepts Perceived as Difficult by Turkish High School Students”. Journal of Education, 145-150.

29. Mastropieri, M.A, et al., (2005). Case studies in co-teaching in the content areas successes, Failures, And challenges. Intervention in school and clinic, 40(5), 260-270.

30. Keeves, J \& Kotte, D. (1992). Disparities between the sexes in science education. Elmsford, NY: Pergamon.

31. Osborne, J., et al. (2003). Attitudes towards science; a review of the literature and its implications. International journal of science education. Vol. 25 (9), 1049-1079.

32. Achor, E.C \& Agbidye, A. (2014) Students Perceived Difficult Concepts and its Biology Laboratory Environment education. Acad., 5(3): 180-186.

33. Dugan, K, \& Letterman, M. (2008). Student appraisals of collaborative teaching. College Teaching, 56(1), 11-15. 